Invited / Invitado

\title{
Lidar/photometer techniques for desert and volcanic dust profiling: Retrieval of particle optical and microphysical properties
}

\author{
Albert Ansmann(*), Ulla Wandinger \\ Leibniz Institute for Tropospheric Research, Permoserstraße 15, Leipzig 04318, Germany \\ ${ }^{(*)}$ Email: albert@tropos.de \\ Received / Recibido: 24/02/2014. Accepted / Aceptado: 07/04/2014. \\ DOI: http://dx.doi.org/10.7149/OPA.47.2.79
}

\begin{abstract}
:
Different lidar/photometer methods are now available which allow us to derive optical and microphysical properties of irregularly shaped aerosol particles such as desert or volcanic dust aerosol particles. The advantage and limits of the different techniques are illuminated. The use of the polarization lidar is of advantage because no critical assumptions such as the spheroidal particle model are required in the data analysis.
\end{abstract}

Key words: Polarization Lidar, Dust Optical and Microphysical Properties, Non-Spherical Particles.

\section{REFERENCES AND LINKS / REFERENCIAS Y ENLACES}

[1]. J. Wagner, A. Ansmann, U. Wandinger, P. Seifert, A. Schwarz, M. Tesche, A. Chaikovsky, O. Dubovik, "Evaluation of the lidar/radiometer inversion code (LIRIC) to determine microphysical properties of volcanic and desert dust", Atmos. Meas. Tech. 6, 1707-1724 (2013). DOI

[2]. A. Ansmann, P. Seifert, M. Tesche, U. Wandinger, "Profiling of fine and coarse particle mass: Case studies of Saharan dust and Eyjafjallajökull/Grimsvötn volcanic plumes", Atmos. Chem. Phys. 12, 9399-9415 (2012). DOI

[3]. A. Lopatin, O. Dubovik, A. Chaikovsky, P. Goloub, T. Lapyonok, D. Tanré, P. Litvinov, "Enhancement of aerosol characterization using synergy of lidar and sun-photometer coincident observations: The GARRLiC algorithm", Atmos. Chem. Phys. Discuss. 6, 2253-2325 (2013). DOI

[4]. D. Müller, I. Veselovskii, A. Kolgotin, M. Tesche, A. Ansmann, O. Dubovik, "Vertical profiles of pure dust and mixed smoke-dust plumes inferred from inversion of multiwavelength Raman/polarization lidar data and comparison to AERONET retrievals and in situ observations", Appl. Opt. 52, 3178-3202 (2013). DOI

\section{Introduction}

The recent volcanic eruptions in northern Europe as well as in the South America emphasized the importance of remote-sensing methods which permit the separation of finemode and coarse-mode particles in the troposphere as a function of height. In the case of air traffic security, the main goal here is the quantification of particle volume and mass concentrations in lofted dust layers. There is also a strong request for vertically resolved aerosol observations from the atmospheric science community to improve our understanding of aerosol radiative effects and aerosol-clouddynamics interaction. The aerosol influence can be very different in the polluted boundary layer (containing mainly local and regional aerosols) and in the free troposphere (dominated by regional and longrange aerosol transport).

Presently, efforts are undertaken in the framework of the European Aerosols, Clouds and Trace gases Research Infrastructure Network (ACTRIS) to make complementary use of different measurement techniques such as lidar (aerosol vertical profiling) and sun-sky photometry (spectrally resolved optical aerosol 
characterization) at combined European Aerosol Research Lidar Network (EARLINET) and Aerosol Robotic Network (AERONET) stations. In this contribution we will compare results obtained with the recently developed Lidar/Radiometer Inversion Code (LIRIC) which was designed as a universal code for processing lidar/photometer network data applicable to many different instrumental conditions and technical approaches, and respective retrieval products obtained with the Polarization Lidar Photometer Network (POLIPHON) technique $[1,2]$. The recently introduced Generalized Aerosol Retrieval from Radiometer and Lidar Combined Data (GARRLiC) [3] can be regarded as an extended version of LIRIC. The fourth method is the traditional lidar inversion technique introduced by D. Müller 15 years ago and now extended by I. Veselovskii to cover irregularly shaped particles in addition [4].

The important difference between LIRIC, GARRLIC, and the inversion method on the onehand side and the POLIPHON technique is that the first three methods are critically based on the use of a spheroidal particle model. It is assumed that the optical properties of the nonspherical, irregularly shaped coarse dust particles (desert dust, volcanic dust) can be sufficiently well described by an ensemble of randomly oriented spheroidal dust particles with homogeneous mineralogical composition throughout the dust particle size distribution. However, this spheroidal particle model causes critical uncertainties when lidar and thus $180^{\circ}$ scattering gets involved in the data analysis.

In this contribution we compare the LIRIC (representing the first three methods) and the POLIPHON results in terms of profiles of desert and volcanic dust optical properties such as the lidar ratio and depolarization ratio and the wavelength dependence of these quantities as well as in terms of profiles of microphysical properties such as particle volume and mass concentrations to investigate the impact of the spheroidal particle model.

\section{Instrumentation}

Multiwavelength Raman/polarization lidars are most useful to provide the required input data for the LIRIC data analysis but also for comparisons of the LIRIC results with directly measured spectra of lidar ratio, backscatter- and extinction-related Ångström exponents, and depolarization ratios. For LIRIC, the transmission of laser radiation at 355,532 , and $1064 \mathrm{~nm}$ is required.

Multiwavelength Raman/polarization lidars are most useful to provide the required input data for the LIRIC data analysis but also for comparisons of the LIRIC results with directly measured spectra of lidar ratio, backscatter- and extinction-related Ångström exponents, and depolarization ratios. For LIRIC, the transmission of laser radiation at 355,532 , and $1064 \mathrm{~nm}$ is required.

\subsection{LIRIC}

LIRIC uses profiles of elastic-backscatter lidar return signals at 355, 532, and $1064 \mathrm{~nm}$ and, as a priori assumptions, AERONET photometer retrieval products (column-integrated particle size distributions, composition, complex refractive index, and particle shape). Column values of the volume-specific backscatter and extinction coefficients separately for spherical and non-spherical particles in the fine-mode as well as in the coarse-mode can be estimated. These volume-specific backscatter and extinction values are important input data for LIRIC.

Products of this synergistic data analysis are height profiles of particle backscatter and extinction coefficients at the three wavelengths, and particle volume and mass concentration profiles separately for fine-mode and coarsemode particles. Main goal of the LIRIC approach is to create a height-resolved data set of particle optical and microphysical properties which is in full agreement with the respective columnintegrated findings from the sun/sky photometer observations. The recently introduced Generalized Aerosol Retrieval from Radiometer and Lidar Combined Data (GARRLiC) [3] can be regarded as an extended version of LIRIC. The GARRLiC concept pursues an even deeper synergy of lidar and radiometer data in the retrievals, e.g., by using the lidar profile information to improve the AERONET retrievals. 
The inversion of AERONET sky radiance measurements to obtain microphysical aerosol properties is well established. The spheroidal particle model is successfully applied to the inversion of AERONET sun/sky photometer data to properly derive microphysical properties of desert dust. However, the way the spheroidal particle model influences the AERONET retrievals of dust properties is quite different from the way, the spheroidal particle model influences lidar applications and therefore the LIRIC results. In the case of AERONET, the complete phase function is fitted to the almucantar sky-brightness data such that the phase function reproduces the almucantar data. In contrast, lidar backscatter data are representative of the sky brightness at just one scattering angle of exactly $180^{\circ}$. Whether the spheroidal particle model is applicable to lidar observations remains an open question.

\subsection{POLIPHON}

An alternative approach for the retrieval of particle volume and mass concentration profiles is the single-wavelength POLIPHON technique [2]. The method is based on measured profiles of the particle linear depolarization ratio and the lidar ratio at $532 \mathrm{~nm}$ and does not require the assumption of a specific particle shape. In this depolarization-ratio-based method it is assumed that the fine-mode-related backscatter and extinction coefficients are exclusively caused by non-depolarizing spherical particles (i.e., fine-mode aerosol fraction) and that the coarse mode consists of strongly lightdepolarizing non-spherical particles. If the particle depolarization ratio is $\geq 0.31$ in Saharan dust layers, the fine-mode particle fraction is set to $0 \%$. If the $532-\mathrm{nm}$ depolarization ratio is $\leq 0.02$, the coarse-mode fraction is set to $0 \%$. For depolarization ratios from 0.02 to 0.31 mixtures of spherical (fine mode) and non-spherical particles (coarse mode) are given and these fractions can be separated by means of the particle depolarization ratio. For volcanic dust, the data analysis is the same, except the volcanic depolarization ratio is set to 0.34 [2].

As it is the case for the LIRIC method, the POLIPHON technique makes use of photometerderived volume-specific extinction coefficients. The values can directly be computed from volume concentrations $V_{f}$ and $V_{c}$ and AOTs $\tau_{\text {ext,f }}$ and $\tau_{\text {ext,c }}$ downloaded from the AERONET website. The specific extinction coefficients are almost insensitive to particle shape effects, in contrast to scattering properties computed for a scattering angle of $180^{\circ}$ (as required in the LIRIC data analysis). The profiles of particle mass concentrations for spherical particles (fine mode) and non-spherical particles (coarse mode) are finally retrieved from the volume concentration profiles which, in turn, are computed from the basic particle backscatter and extinction coefficients.

The main advantage of the POLIPHON method is that a particle shape model for irregularly shaped dust particles is not required. A critical aspect is here that fine and coarse mode fractions as determined with LIRIC may not be well represented by these spherical and non-spherical particle fractions. A significant part of the non-spherical dust particles may belong to the fine mode, but are interpreted as coarse-mode particles when applying POLIPHON, i.e, when the non-spherical particle fraction is assumed to be identical with the coarse mode fraction.

\section{Results}

We focus on two cases with aerosol layers containing a considerable amount of irregularly shaped coarse-mode particles. The first case refers to a strong Saharan dust outbreak towards Europe in May 2008. The second case covers the aerosol conditions after the eruption of the Icelandic volcano Eyjafjallajökull in April 2010. All the results presented at the workshop are published [1-3], and thus are not given here again.

In the Saharan dust case, typical uncertainty features (biases) for desert dust introduced by the use of the spheroidal particle model were found in the LIRIC-derived optical properties (too high lidar ratios, too low depolarization ratios at 355 and $532 \mathrm{~nm}$ ). However, coarsemode particle mass concentrations obtained with LIRIC and POLIPHON showed acceptable agreement. In the complex volcanic aerosol case, also considerable deviations of the LIRICderived optical properties from the direct 
Raman/polarization lidar observations were found. Coarse-mode particle mass values also deviated from the ones obtained with the alternative POLIPHON technique.

\section{Conclusions}

It is too early to draw general conclusions from the LIRIC/POLIPHON comparison studies done so far in the framework of EARLINET and ACTRIS activities. More scenarios with very different aerosol loadings, layering, and mixing including aerosol types from marine, over urban and biomass-burning aerosol to mineral and volcanic dust must be analyzed and discussed in order to further improve the synergistic lidar/photometer analysis techniques. Other particle shape models may be developed and tested to better reproduce the $180^{\circ}$ scattering properties of irregularly shaped particles. Much more work of comparisons of LIRIC results, Raman lidar products, and also independent airborne in situ aerosol observations would be desirable.

\section{Acknowledgements}

The research leading to these results has been partly funded by the European Union Seventh Framework Programme (FP7/2011-2015) under grant agreement $\mathrm{n}-262254$ (ACTRIS project). 